\title{
Juvenile Aggressive Trabecular Ossifying Fibroma of Mandible: A Rare Case Report
}

\author{
${ }^{1}$ Abhishek Sanjay Ghule, ${ }^{2}$ Deepa Das Achath, ${ }^{3}$ Preeti Kanchan-Talreja, ${ }^{4}$ Sunanda Bhatnagar
}

\begin{abstract}
Fibroosseous lesions of the jaws, including juvenile ossifying fibroma (JOF), pose diagnostic and therapeutic difficulties due to their clinical, radiological, and histological variability. There are two histological varieties of it, one as psammomatoid type and second as trebacular type; here, we present a trebacular type, which is a rare variety. After the clinical examination, radiological and histological analysis, it was diagnosed as juvenile trebacular ossifying fibroma. Although JOF is an uncommon clinical entity, its aggressive local behavior and high recurrence rate means that it is important to make an early diagnosis, apply the appropriate treatment, and, especially, follow-up the patient over the long term.
\end{abstract}

Keywords: Fibroosseous lesions of the jaw, Juvenile aggressive trabecular ossifying fibroma, JOF.

How to cite this article: Ghule AS, Achath DD, KanchanTalreja P, Bhatnagar S. Juvenile Aggressive Trabecular Ossifying Fibroma of Mandible: A Rare Case Report. J Contemp Dent 2016;6(1):45-51.

\section{Source of support: Nil}

\section{Conflict of interest: None}

\section{INTRODUCTION}

Fibroosseous lesions of the cranial and facial bones are usually benign and tend to grow slowly. Benign fibroosseous lesions have histopathological features similar with fibrous dysplasia, ossifying fibroma, and cementoossifiying dysplasia. ${ }^{1,2}$

Ossifying fibroma, a rare tumor entity, is a welldemarcated, benign, fibroosseous tumor with capsule composed of metaplastic bone, fibrous tissue, and varying amounts of osteoid. ${ }^{3-5}$ The ossifying fibromas are subdivided into conventional and juvenile clinicopathologic subtypes. ${ }^{3}$ Conventional ossifying fibromas are usually slow growing and generally seen in the 3rd and 4th decades of life. ${ }^{6,7}$ They are treated with simple curettage and the recurrence is rare. ${ }^{8}$ It affects people of all ages, but

\footnotetext{
${ }^{1}$ Postgraduate Student, ${ }^{2}$ Professor, ${ }^{3,4}$ Reader

${ }^{1-4}$ Department of Oral Medicine and Radiology, YMT Dental College and Hospital, Navi Mumbai, Maharashtra, India

Corresponding Author: Abhishek Sanjay Ghule, Postgraduate Student, Department of Oral Medicine and Radiology, YMT Dental College and Hospital, Navi Mumbai, Maharashtra India, Phone: +09920223417, e-mail: dr.abhishekghule@ gmail.com
}

in contrast to the form seen in adults, the juvenile form is clinically more aggressive and tends to be recurrent. ${ }^{3}$

According to the new edition of the classification of the World Health Organization (WHO), ${ }^{9}$ ossifying fibromas that appear as fast growing mass between 5 and 15 years of age, radiologically well-bordered, and consistent with ossifying fibroma histologically, are referred as juvenile ossifying fibroma (JOF).

Juvenile ossifying fibroma appears at an early age and in $79 \%$ of the patients is diagnosed before the age of 15. 2, 3,10 Males and females are equally affected. ${ }^{11}$ Juvenile ossifying fibroma originates from periodontal ligament and accounts for $2 \%$ of oral tumors in children. ${ }^{12,13}$ The JOF is located mainly (85\%) in facial bones, in some cases $(12 \%)$ in calvarium, and very seldom $(3 \%)$ extracranially. ${ }^{2}$ Ninety percent of the lesions located in the face region involve the sinuses, mainly the maxillary antra. ${ }^{2}$ Mandibular lesions are seen in $10 \%$ of the cases. ${ }^{2,14}$ The tumor is well circumscribed by a tiny sclerotic shell of bone. It appears locally aggressive with cortical disruption and involvement of many adjacent anatomical structures. This lesion has predominating soft tissue consistency with variable amounts of internal calcification and/or linear or irregular focal bone. ${ }^{2}$ It usually shows a low density mass due to cystic changes on computed tomography (CT) scans. Following intravenous injection of iodinated contrast, the lesion may show diffuse appearance enhancement. $^{2}$

Histologically, JOF is characterized by the presence of cellular fibrous stroma, garland-like bony strands, and cement particles. ${ }^{2,6,11,13}$ The JOFs are classified into two distinct clinicopathological entities: The trabecular and the psammomatoid types. Trabecular JOF is distinguished by the presence of trabeculae of fibrillar osteoid and woven bone and psammomatoid JOF is characterized by the presence of small uniform spherical ossicles that resemble psammoma bodies. ${ }^{14,15}$ Psammomatoid JOF is reported more commonly than trabecular JOF. ${ }^{14,16}$ Psammomatoid JOF occurs predominantly in the sinonasal and orbital bones, and trabecular JOF predominantly affects the jaws. Psammomatoid JOF has aggressive behavior and it has a very strong tendency to recur. ${ }^{15-17}$

An accurate diagnosis of JOF is made by correlating the clinical, radiological features, and histopathological findings. ${ }^{2}$ 
A case of juvenile trabecular ossifying fibroma (JTOF) of the right mandible in a 34-year-old male is presented here. The rarity of the case is the age of occurrence that is unusual for JTFO, but the lesion was undetected for a long time. The lesion was so aggressive, as it caused expansile destruction of the right mandible. Very few cases of JTOF have been reported in the literature that makes this case a unique one.

\section{CASE REPORT}

A 34-year-old male patient came with a chief complaint of painless swelling in his lower right jaw since last 15 years. Patient gave history of getting hit on the jaw with a cricket ball at school 20 years back. There was pain and swelling following the trauma, but it subsided within a few days without any treatment. However, after 5 years, he noticed a small swelling about the size of a coin in the same region. He neglected it, as it did not cause any discomfort. After a few years, he noticed that the swelling gradually increased in size for about 10 years and then there was a rapid increase in the size of the swelling during the last 5 years, and has reached the present dimension. There has been no history of bleeding, discharge, and parasthesia associated with the swelling. On general examination, the patient was conscious, cooperative, and well-oriented to time, place, and person. He was healthy, well-built, and well nourished. All vital signs were within the normal limits. On extraoral examination, there was a gross facial asymmetry due to a diffuse swelling on the right side of the lower face (Figs 1 to 3 ).

The swelling measured approximately about $10 \times 6 \mathrm{~cm}$ in size anterioposteriorly, extending from right lower

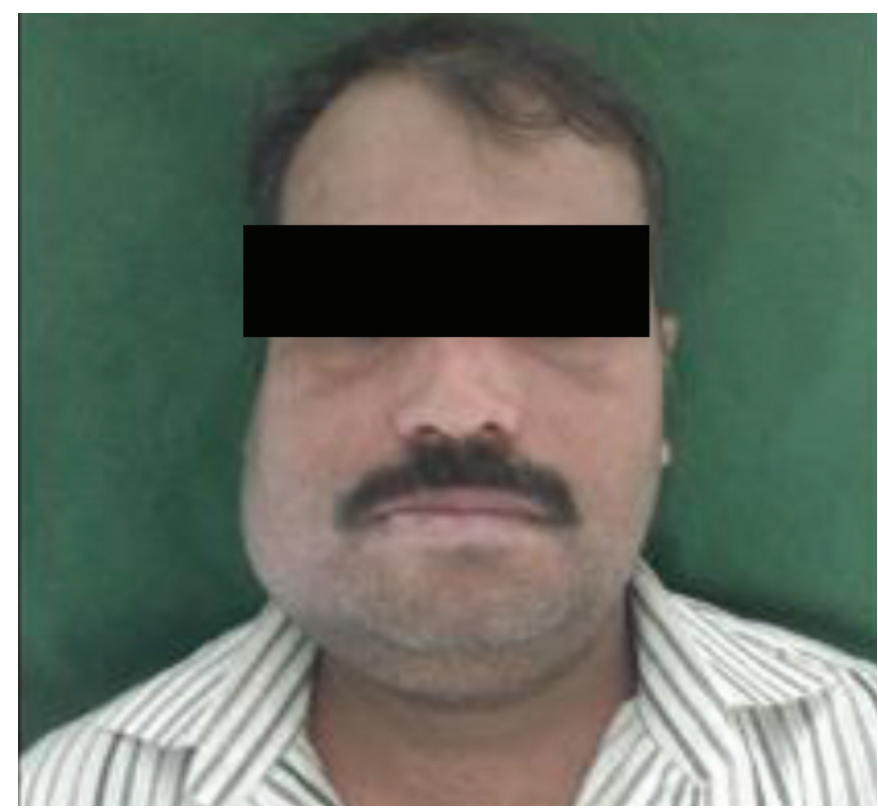

Fig. 1: Front facial profile

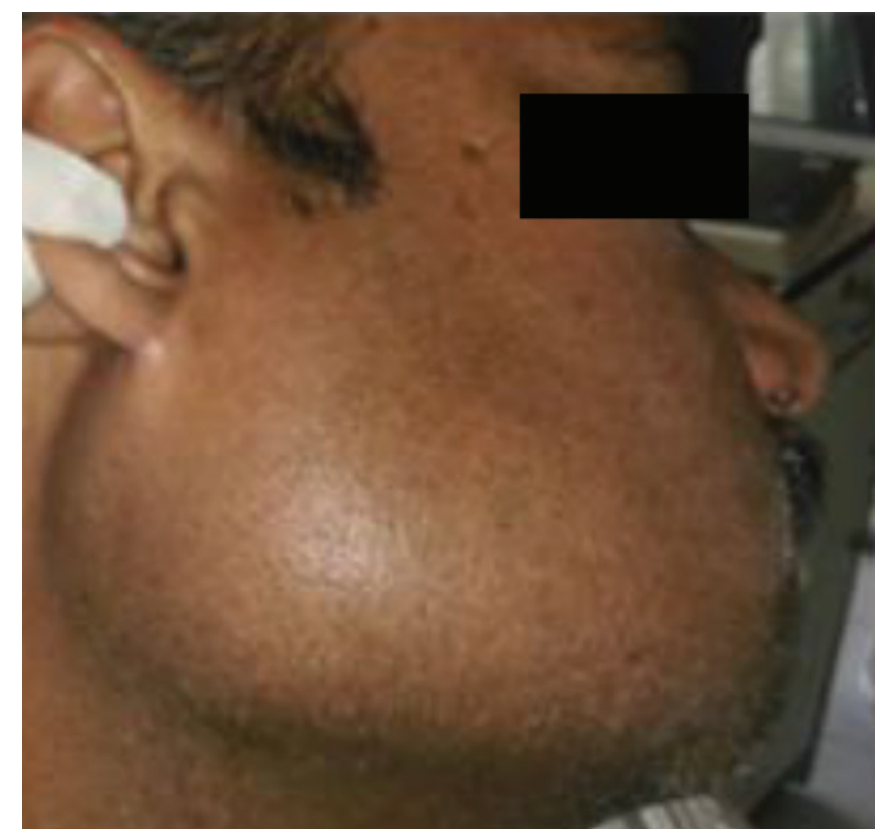

Fig. 2: Right lateral facial profile

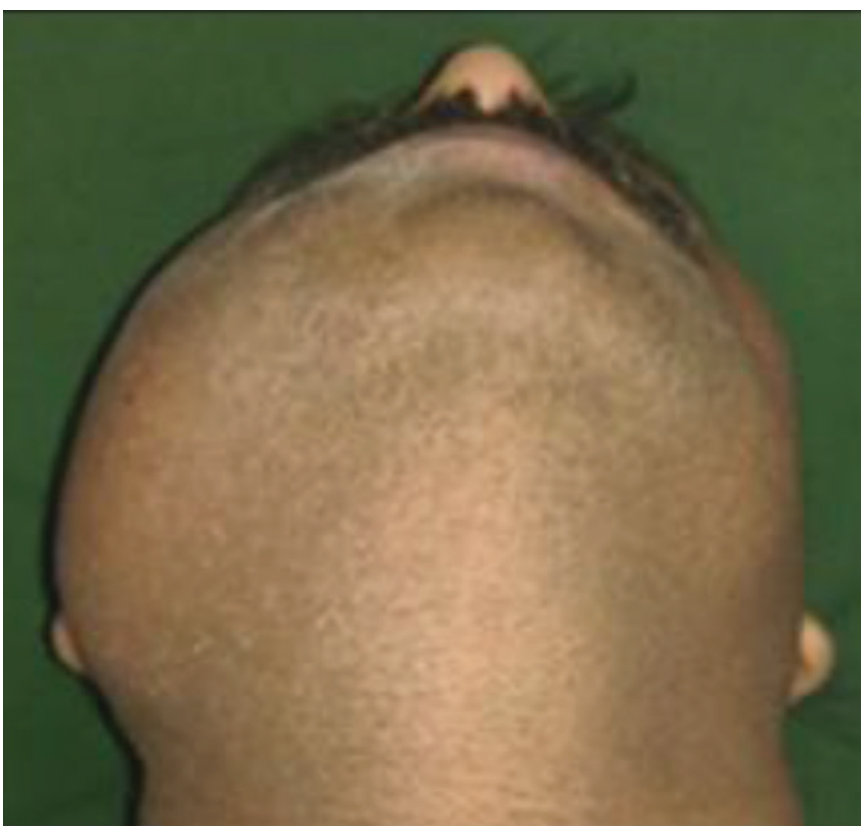

Fig. 3: Expansion of the right lower face

para symphyseal region till $2.5 \mathrm{~cm}$ posterior to the right ear. Superoinferiorly, it extended from right alatragal line till $1 \mathrm{~cm}$ inferior to the right lower mandibular border. Skin over the swelling was tensed, shiny but without any change in color, scar, or pigmentation. On palpation, the entire inspectory findings were confirmed. The swelling was bony hard, afebrile, and nontender. A single right submandibular lymph node was palpable, tender, and mobile. Intraoral examination revealed obliteration of the right lower buccal vestibule due to the swelling, extending from 43 till the posterior aspect of 48 , which 


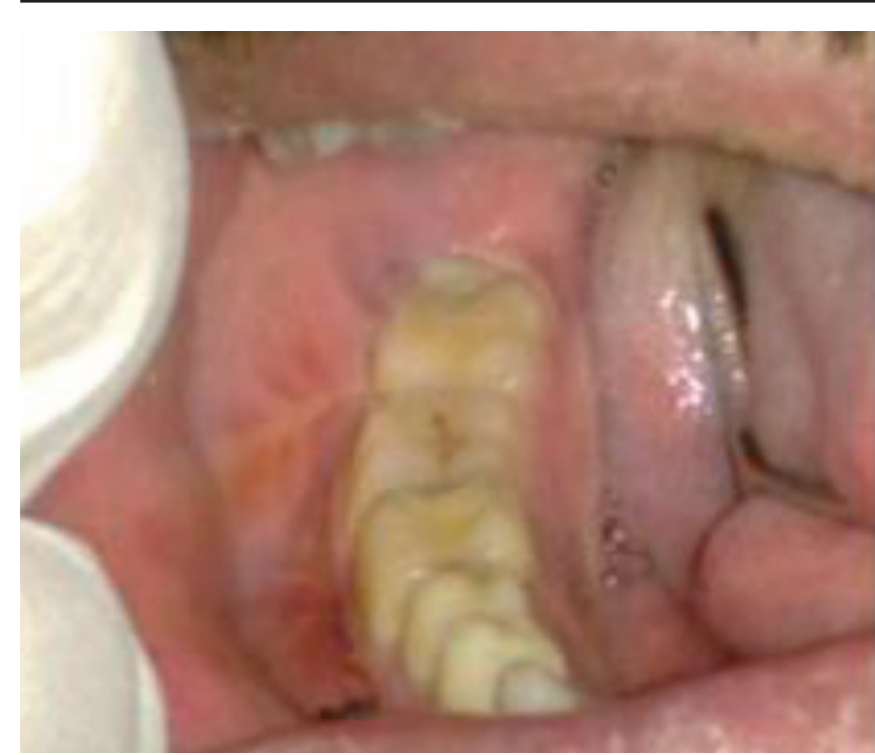

Fig. 4: Intraoral view of lower right mandibular region

on palpation was bony hard in consistency (Figs 1 to 3 ). The swelling expanded the buccal cortical plate with maximum expansion in relation to 47 . The surface of the swelling was of normal color with no sign of discharge. Teeth in this region were normal without any pathology (Fig. 4).

Based on history and clinical examination, a provisional diagnosis of benign odontogenic tumor was given. A differential diagnosis of a fibroosseous lesion was considered.

Orthopantomogram (OPG) (Fig. 5) revealed an expansile mixed lesion on the right side of mandible. The trabecular pattern was altered from the symphyseal region extending posteriorly to the ramus expanding it. In the angle region, the expansion was globular ascending up to the ramus expanding its posterior border involving the condyle obliterating the sigmoid notch and the anterior border of ramus. The internal structure revealed mixed radiolucent radiopaque areas in the anterior aspect and posteriorly a multilocular pattern. Neither there was displacement of teeth in the region nor were the roots resorbed.

Intraoral periapical (IOPA) radiograph from 41 to 48 (Figs 6 to 8) revealed a mixed radiolucent radiopaque lesion in the periapical region with loss of lamina dura in relation to their roots. The radiopacities were patchy with diffuse radiolucent areas in between. Right mandibular lateral occlusal radiograph (Fig. 9) shows a marked expansion of buccal cortical plate from 45 to posteriorly beyond 48 . Here, a homogenous radiopaque pattern with radiolucent locules in the anterior region was appreciated.

A posteroanterior (PA) mandible view (Fig. 10) showed an expansile multilocular lesion in the right mandible

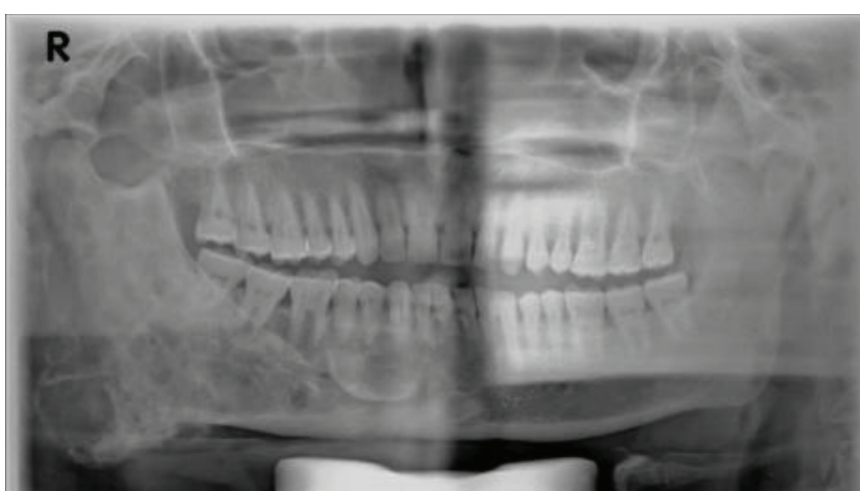

Fig. 5: Orthopantomogram

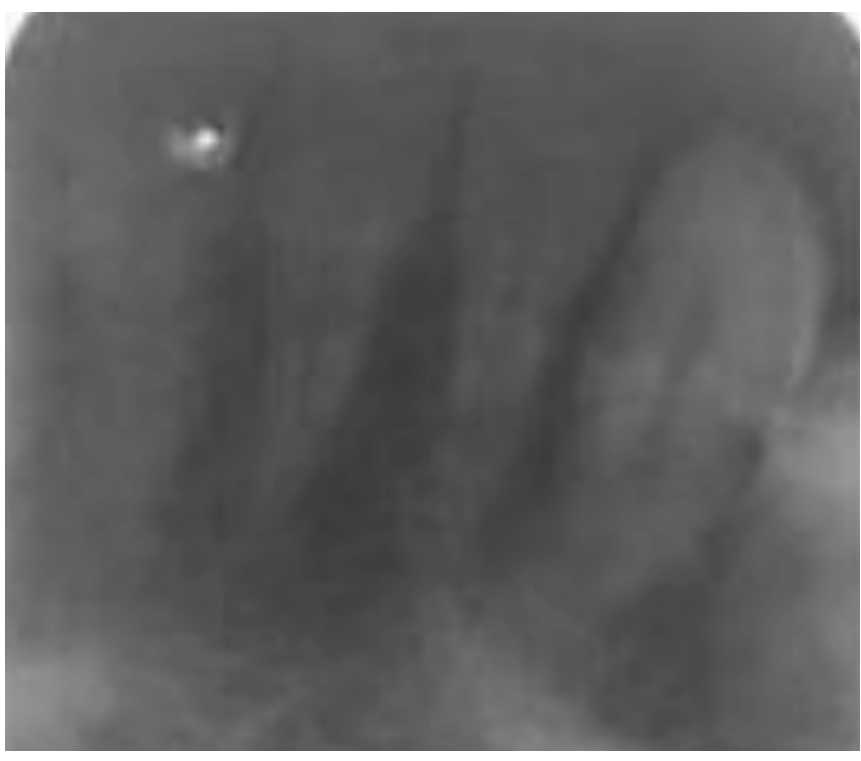

Fig. 6: Intraoral periapical $-41,42,43$

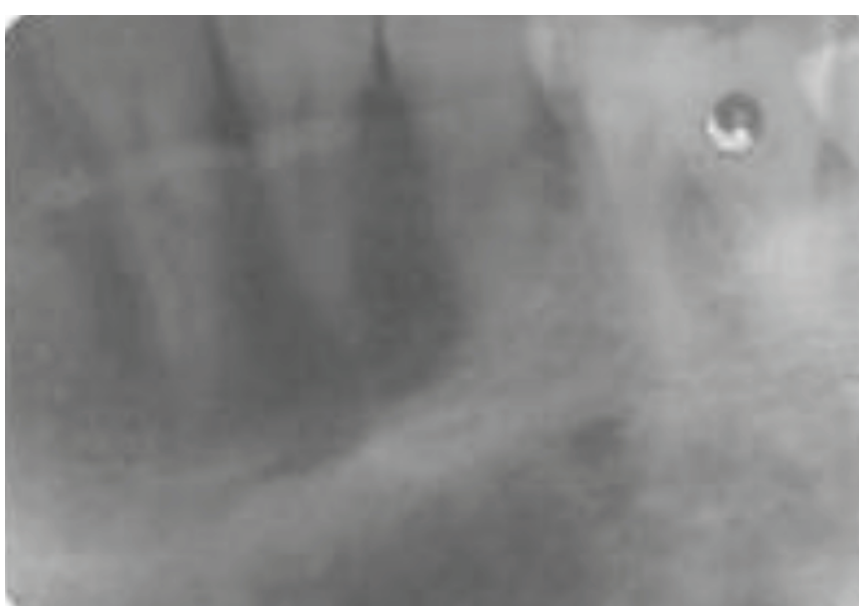

Fig. 7: Intraoral periapical - 44, 45, 46

with a globular expansion of the angle ascending up to the ramus to the condyle. There was irregular expansion of the anterior border of the ramus.

Axial CT scans (Figs 11 to 13) and three-dimensional (3D) reconstruction (Figs 14 to 16) images showed an 


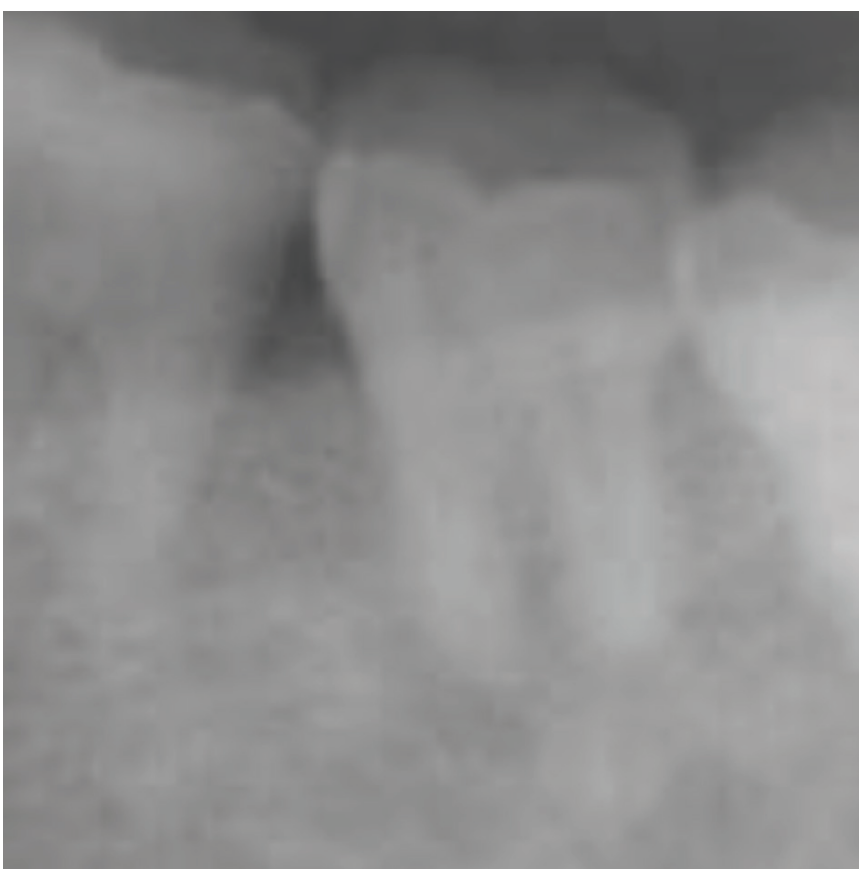

Fig. 8: Intraoral periapical-46, 47, 48

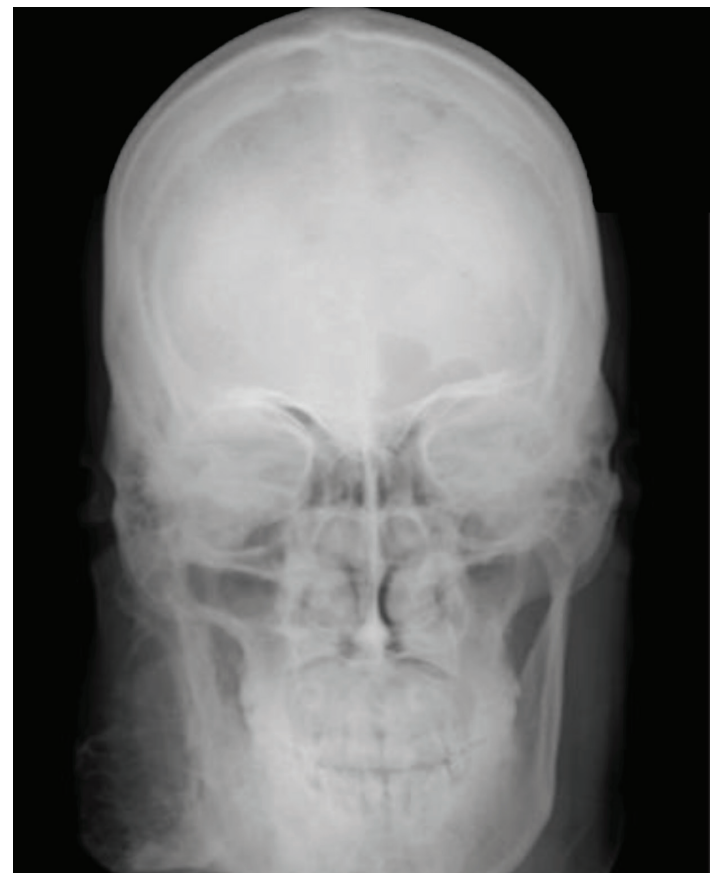

Fig. 10: Posteroanterior mandible

expansile multilocular lesion in the right side of the mandible. The expansion was more in the buccal aspect of the mandible, exaggerated in the angle, involving the ramus, condyle, and coronoid. Small, patchy calcified masses could also be appreciated in the axial sections of CT.

Based on the radiographic pictures, a fibroosseous lesion was considered due to the multilocular radiolucent and patchy calcified areas, with a globular, centrifugal growth pattern in the angle.

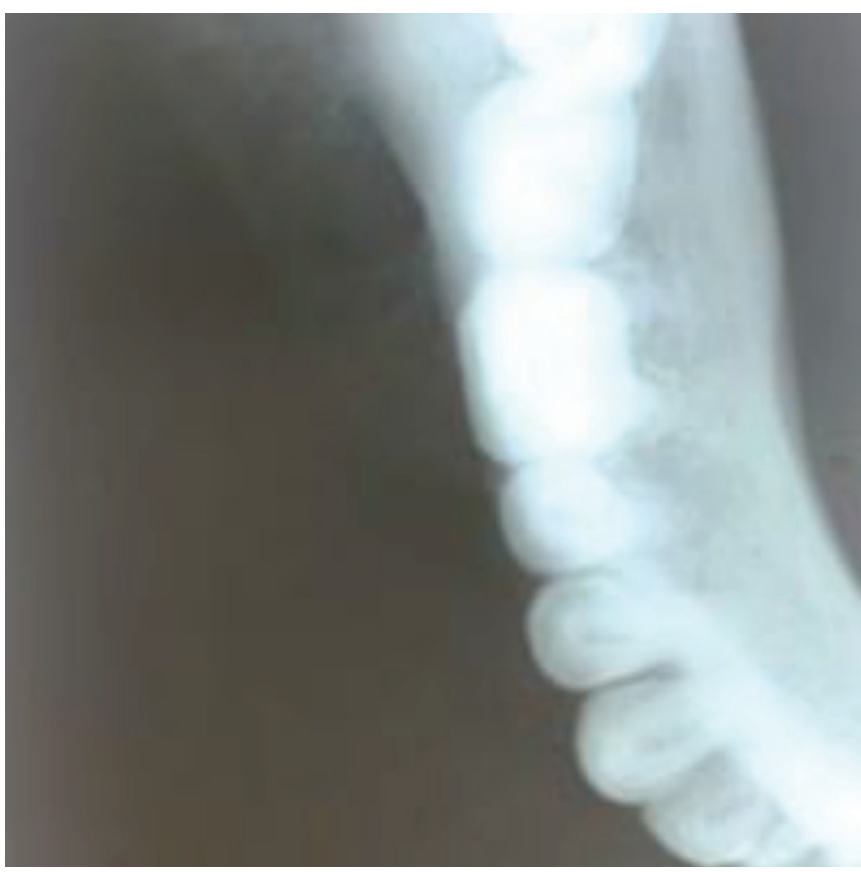

Fig. 9: Right mandibular lateral occlusal radiograph

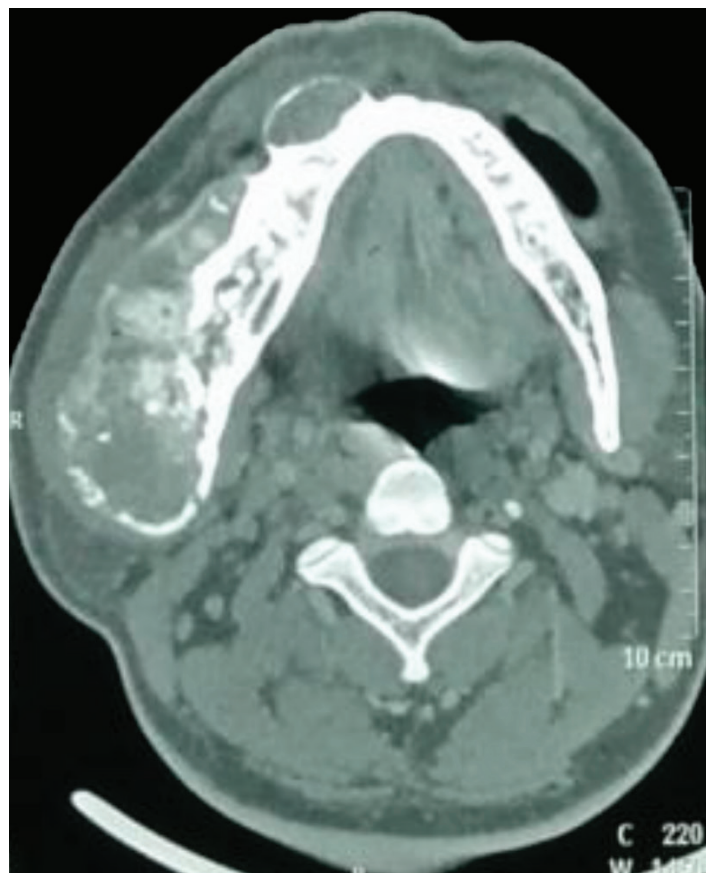

Fig. 11: Computed tomography image

A bone biopsy of the swelling revealed an aggressive type of ossifying fibroma in the mandible. Histopathologic report said the H\&E section photomicrographs (Figs 17 to 19) show highly cellular connective stroma, which is composed of plump fibroblasts, collagen fibers, and many blood vessels; areas of ossification in the form of bony trabeculae and round masses of lamellar bone are seen interspersed throughout the connective tissue. Some of the trabeculae show osteoblastic rimming indicative of forming bone. 


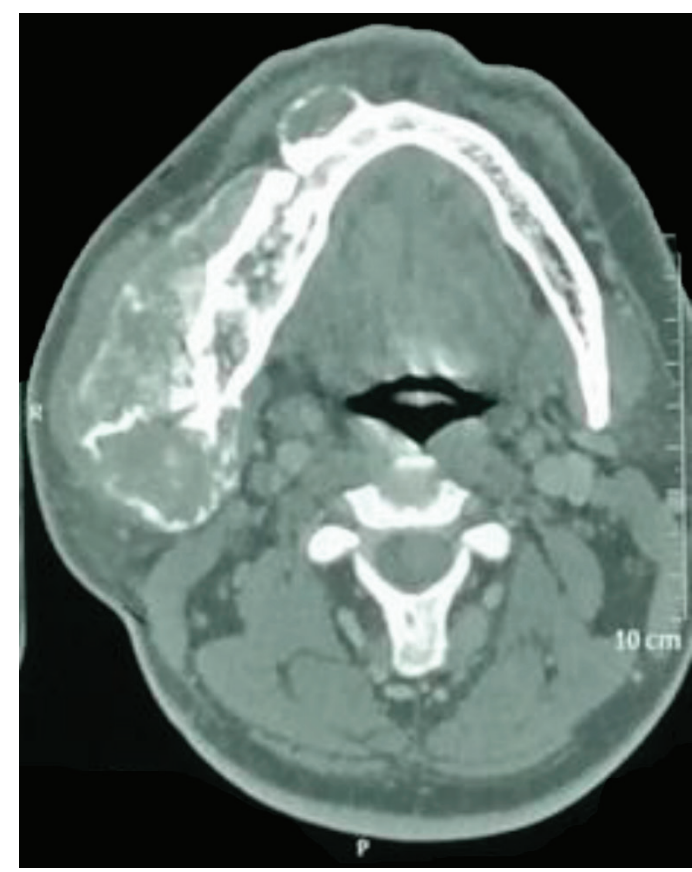

Fig. 12: Computed tomography image axial view

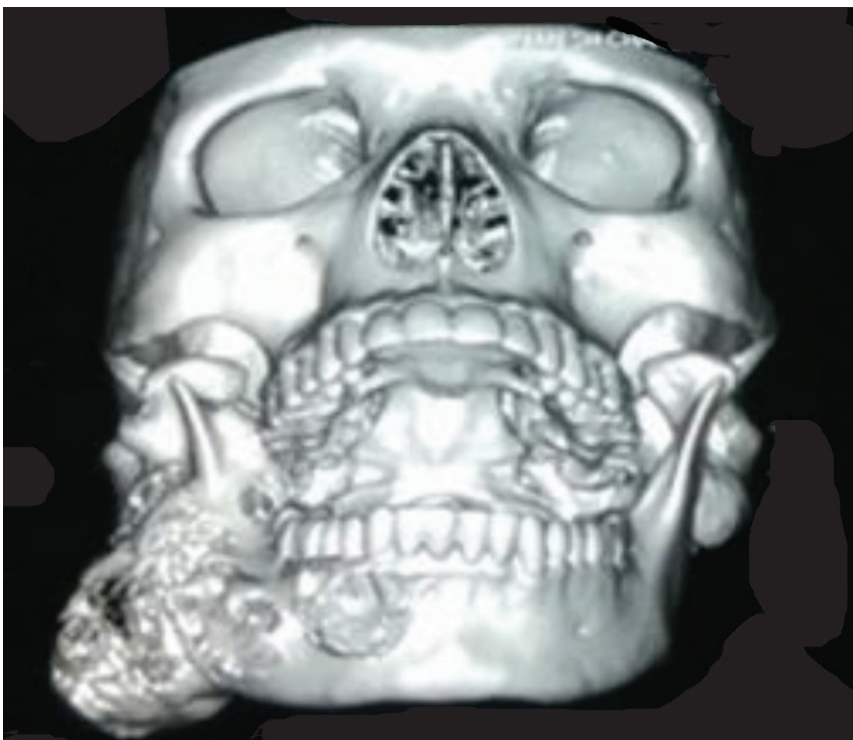

Fig. 14: Three-dimensional reconstruction frontal aspect

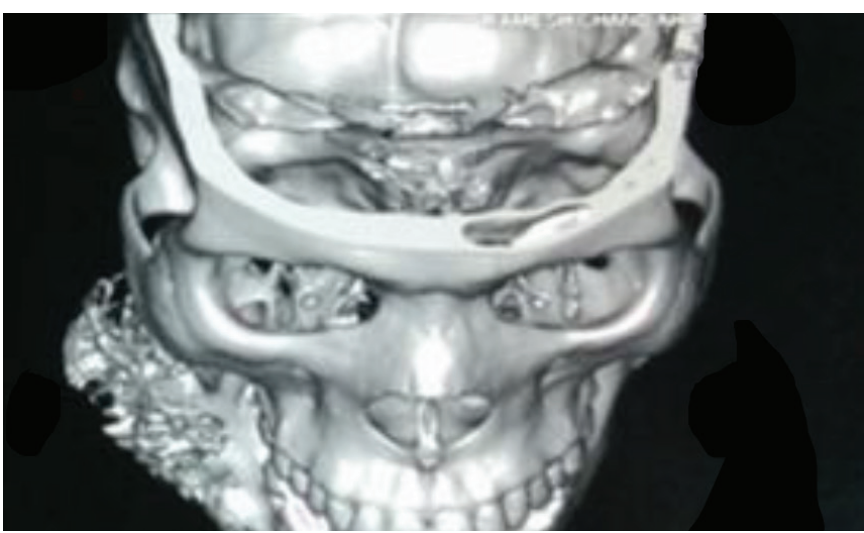

Fig. 16: Three-dimensional reconstruction frontosuperior aspect

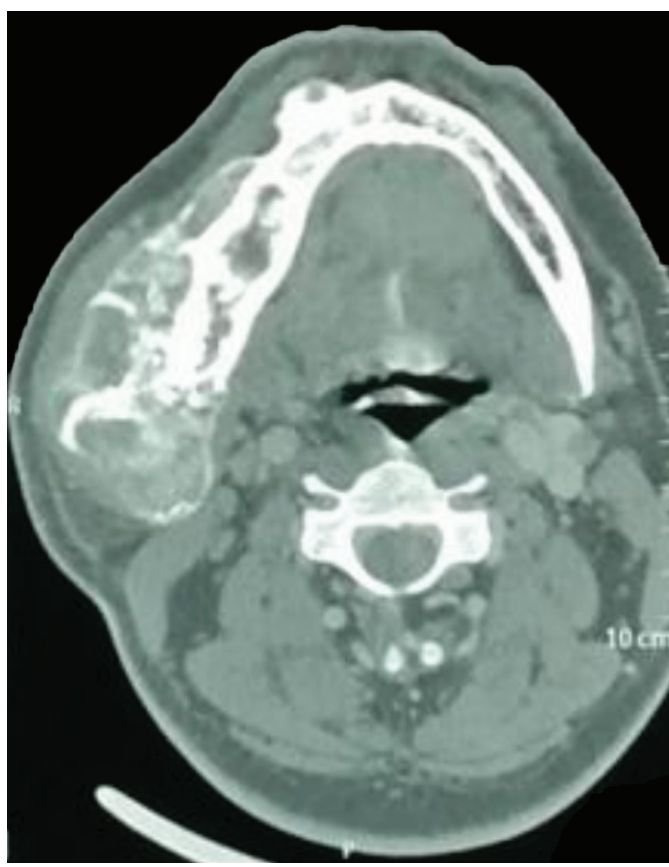

Fig. 13: Computed tomography image axial view

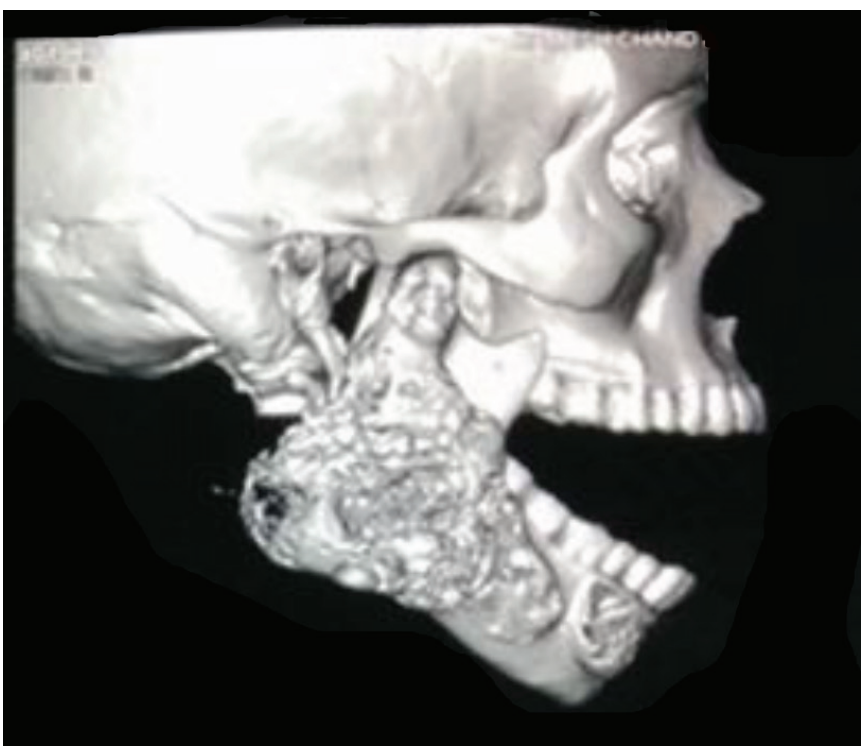

Fig. 15: Three-dimensional reconstruction lateral aspect

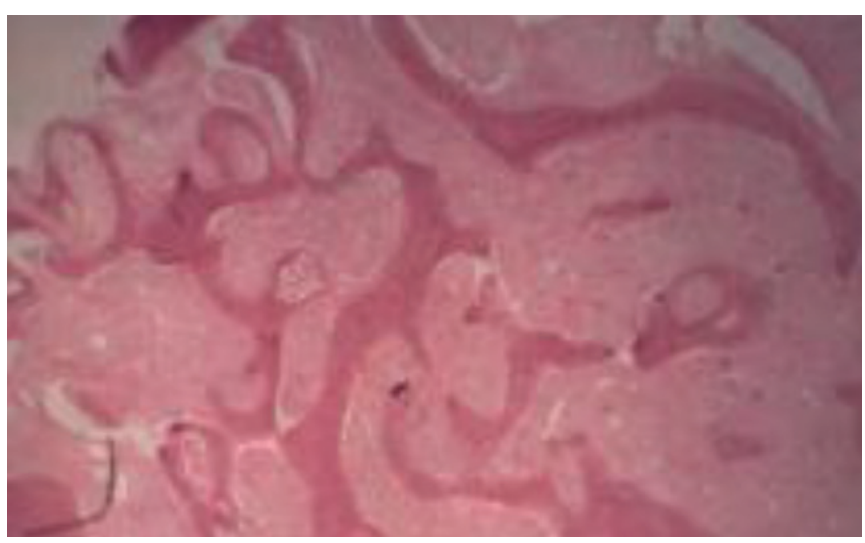

Fig. 17: Histopathology photomicrogram 


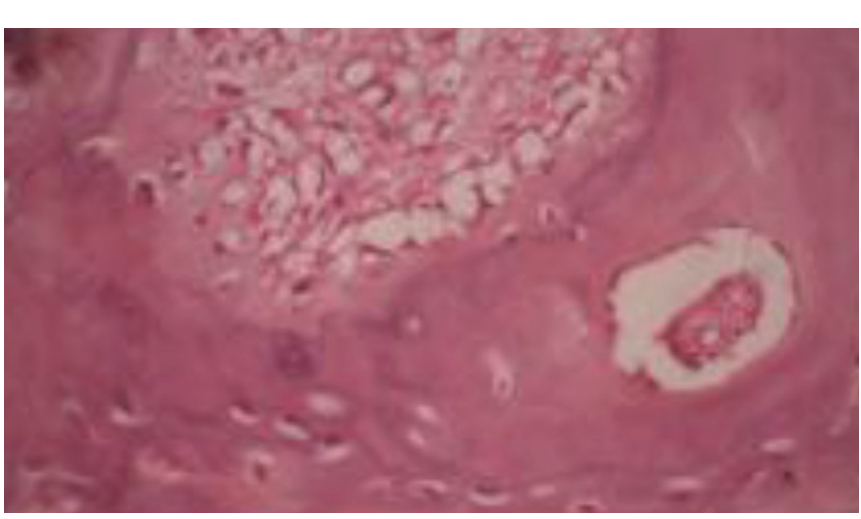

Fig. 18: Histopathology photomicrogram

\section{DISCUSSION}

Most benign fibroosseous lesions of jaws are asymptomatic and slowly progressing. Moreover, an unusual clinical presentation with apparent aggressive and destructive growth may be expected when the lesion is encountered in a younger patient. ${ }^{18,19}$ In our patient, the lesion was initiated at a younger age but was neglected by the patient and/or was not detected at that time.

Juvenile ossifying fibroma is a relatively rare fibroosseous lesion of the jaws characterized by its early age of occurrence, the location, radiological appearance, and the tendency to recur. ${ }^{25}$ Juvenile ossifying fibroma affects both males and females equally without any significant gender predilection. However, some researchers report that it is more common among men. ${ }^{20}$ The patient whose case is reported here is also a 34-year-old male. In contrast, Johnson et $\mathrm{al}^{20}$ stated that mandibular tumors are more frequently common in girls between the age of 5 and 11 years or during the 2nd to 4 th decades of life. ${ }^{6}$

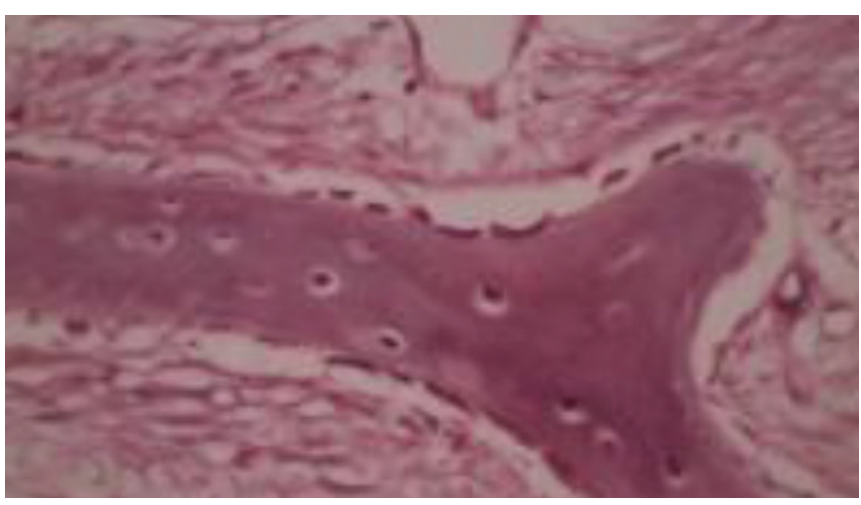

Fig. 19: Histopathology photomicrogram

A few cases of facial trauma have been suggested as a possible etiologic factor in the JOF development ${ }^{10}$ as was found in this patient also.

Juvenile ossifying fibroma is characterized as an expansile, yet with well-defined sclerotic borders, locally aggressive, and destructive at cortex on CT scan. This lesion is observed as a soft tissue mass with internal calcification, linear or irregular bone $\mathrm{foci}^{2,21-23}$ as was observed in our case.

Ong and $\mathrm{Siar}^{24}$ presented JOF as a progressively growing lesion that can attain an enormous size with resultant deformity if left untreated. They presented a case of large cemento-ossifying fibroma involving the left mandible in a male patient. The long-lasting history of untreated JOF resulted to spontaneous fracture of mandible. Furthermore, if JOF does not have adequate surgical treatment, it may have a high rate of recurrence., ${ }^{4,24}$ The recurrences are generally seen at an early stage and they are more aggressive than primary lesions. ${ }^{4}$

As per Table $1,{ }^{15}$ for differentiation of ossifying fibroma, juvenile aggressive trabecular ossifying fibroma,

Table 1: A working classification of the three clinicopathological variants of ossifying fibroma ${ }^{15}$

\begin{tabular}{|c|c|c|c|}
\hline & Ossifying fibroma & Juvenile trabecular ossifying fibroma & Juvenile psammomatoid ossifying fibroma \\
\hline Age (mean) & $10-50$ years $(35)$ & $2-30$ years $(10)$ & 3 months -72 years $(20)$ \\
\hline Female:male & $2: 1$ & $1.2: 1$ & $1.3: 1$ \\
\hline Site & $\begin{array}{l}\text { Tooth-bearing areas } \\
\text { Mandible } 70 \% \\
\text { Maxilla } 30 \%\end{array}$ & $\begin{array}{l}\text { Mandible } 50 \% \\
\text { Maxilla } 44 \% \\
\text { Sinonasal } 6 \%\end{array}$ & $\begin{array}{l}\text { Sinonasal } 62 \% \\
\text { Maxilla } 20 \% \\
\text { Mandible (ramus) } 10 \% \\
\text { Cranium } 8 \%\end{array}$ \\
\hline Radiology & $\begin{array}{l}\text { Well circumscribed } \\
\text { Unilocular } \\
\text { Variable radiopacity }\end{array}$ & $\begin{array}{l}\text { Well circumscribed } \\
\text { Speckled calcifications }\end{array}$ & $\begin{array}{l}\text { Well circumscribed } \\
\text { Expands and fills paranasal sinuses- } \\
\text { "aggressive pattern" tends to be radiopaque }\end{array}$ \\
\hline Histopathology & $\begin{array}{l}\text { Cellular fibrous tissue, storiform } \\
\text { pattern, separate trabeculae } \\
\text { of woven boneoccasional } \\
\text { spherical, psammomatoid } \\
\text { calcifications, encapsulated }\end{array}$ & $\begin{array}{l}\text { Densely cellular, immature osteoid } \\
\text { and in trabecular pattern, osteoblast } \\
\text { rimming and cellular osteoid. }\end{array}$ & $\begin{array}{l}\text { Densely cellular, spherical cementumlike } \\
\text { psammomatoid calcifications, may } \\
\text { permeate cancellous bone, myoid areas } \\
\text { giant cells, hemorrhage }\end{array}$ \\
\hline Synonyms & $\begin{array}{l}\text { 1. Cemento-ossifying fibroma } \\
\text { 2. Cementifying fibroma } \\
\text { 3. Periodontoma }\end{array}$ & $\begin{array}{l}\text { 1. Juvenile aggressive ossifiyng fibroma } \\
\text { 2. Juvenile ossifying fibroma WHO } \\
\text { type } \\
\text { 3. Trabecular desoosteoblastoma }\end{array}$ & $\begin{array}{l}\text { 1. Cemento-ossifying fibroma } \\
\text { 2. Juvenile ossfying fibroma with } \\
\text { psammomatoid ossicles } \\
\text { 3. Juvenile ossfying fibroma psammous } \\
\text { desoosteoblastoma }\end{array}$ \\
\hline
\end{tabular}

WHO: World Health Organization 
Juvenile Aggressive Trabecular Ossifying Fibroma of Mandible

Table 2: Differences in clinical and dermograpic presentations of psammomatoid juvenile ossifying fibroma and trabecular juvenile ossifying fibroma (adapted and modified Ref. ${ }^{15}$ )

\begin{tabular}{llllll}
\hline Type & Site & Age & Mean age & Gender & Histopathology \\
\hline Psammomatoid juvenile & More common in & 3 months & 16-33 years & M > F More & Small uniform spherical ossicles \\
ossifying fibroma & sinonasal and orbital bone & 72 years & & common 1.2:1 & resembling psammona bodies \\
Trabecular juvenile & Maxilla > mandible In & 2-12 years & $81 / 2-12$ years & M > F less & Trabeculae of fibrillar osteoid \\
ossifying fibroma & mandible, body > ramus & & & common & and woven bone \\
\hline
\end{tabular}

and juvenile aggressive psammomatoid fibroma, the features of the present case can be diagnosed as juvenile aggressive trabecular ossifying fibroma.

According to the clinical features given by the El Mofty (Table 2) ${ }_{1}^{15}$ which states that a predominance of maxilla for trabecular pattern does not hold good in our case as it is in the mandible. Further, the table mentions about a predominance for body of mandible as compared with ramus. Age does not coincide with our case, as it was detected late but was initiated early. Histopathologically, findings of the biopsy coincide with both Tables 1 and $2 .{ }^{15}$

\section{CONCLUSION}

Although JOF is an uncommon clinical entity, its aggressive local behavior and high recurrence rate means that it is important to make an early diagnosis, to apply the appropriate treatment, and follow-up the patient over the long term. It is also important to evaluate the radiographs and correlate with its clinical findings and confirm with histopathology, as there are limited cases of this entity reported so far.

\section{REFERENCES}

1. MacDonald-Jankowski DS. Fibro-osseous lesions of the face and jaws. Clin Radiol 2004 Jan;59(1):11-25. Review. Erratum in: ClinRadiol 2009 Jan;64(1):107.

2. Khoury NJ, Naffaa LN, Shabb NS, Haddad MC. Juvenile ossifying fibroma: CT and MR findings. Eur Radiol 2002 Dec;12(Suppl 3):S109-S113.

3. Mehta D, Clifton N, McClelland L, Jones NS. Paediatric fibro-osseous lesions of the nose and paranasal sinuses. Int J Pediatr Otorhinolaryngol 2006 Feb;70(2):193-199.

4. Espinosa SA, Villanueva J, Hampel H, Reyes D. Spontaneous regeneration after juvenile ossifying fibroma resection: a case report. Oral Surg Oral Med Oral Pathol Oral Radiol Endod 2006 Nov;102(5):e32-e35.

5. Patil K, Mahima BG, Balaji P. Juvenile aggressive cementoossifying fibroma: a case report. Ind J Dent Res 2003 JanMar;14(1):59-66.

6. Chang CC, Hung HY, Chang JY, Yu CH, Wang YP, Liu BY, Chiang CP. Central ossifying fibroma: a clinicopathologic study of 28 cases. J Formos Med Assoc 2008 Apr;107(4): 288-294.

7. Alsharif MJ, Sun ZJ, Chen XM, Wang SP, Zhao YF. Benign fibro-osseous lesions of the jaws: a study of 127 Chinese patients and review of the literature. Int J Surg Pathol 2009 Apr;17(2):122-134.
8. Zama M, Gallo S, Santecchia L, Bertozzi E, De Stefano C. Juvenile active ossifying fibroma with massive involvement of the mandible. Plast Reconstr Surg 2004 Mar;113(3):970-974.

9. Reichart PA, Philipsen HP, Sciubba JJ. The new classification of head and neck tumours (WHO) — any changes? Oral Oncol 2006 Sep;42(8):757-758.

10. Slootweg PJ, Müller H. Juvenile ossifying fibroma. Report of four cases. J Craniomaxillofac Surg 1990 Apr;18(3):125-129.

11. Bertrand B, Eloy P, Cornelis JP, Gosseye S, Clotuche J, Gilliard C. Juvenile aggressive cemento-ossifying fibroma: case report and review of the literature. Laryngoscope 1993 Dec;103(12):1385-1390.

12. Sharif MA, Mushtaq S, Mamoon N, Khadim MT. Ossifying fibromyxoid tumor of oral cavity. J Coll Physicians Surg Pak 2008 Mar;18(3):181-182.

13. Dominguete PR, Meyer TN, Alves FA, Bittencourt WS. Juvenile ossifying fibroma of the jaw. Br J Oral Maxillofac Surg 2008 Sep;46(6):480-481.

14. LawtonMT,HeisermanJE,CoonsSW, RagsdaleBD,Spetzler RF. Juvenile active ossifying fibroma: report of four cases. J Neurosurg 1997 Feb;86(2):279-285.

15. El-Mofty S. Psammomatoid and trabecular juvenile ossifying fibroma of the craniofacial skeleton: two distinct clinicopathologic entities. Oral Surg Oral Med Oral Pathol Oral Radiol Endod 2002 Mar;93(3):296-304.

16. Thankappan S, Nair S, Thomas V, Sharafudeen KP. Psammomatoid and trabecular variants of juvenile ossifying fibroma: two case reports. Ind J Radiol Imaging 2009 AprJun;19(2):116-119.

17. Solomon M, Khandelwal S, Raghu A, Carnelio S. Psammomatoid juvenile ossifying fibroma of the mandible-a histochemical insight! Int J Dent Sci 2009;7:2.

18. Williams HK, Mangham C, Speight PM. Juvenile ossifying fibroma. An analysis of eight cases and a comparison with other fibro-osseous lesions. J Oral Pathol Med 2000 Jan;29(1):13-18.

19. Waldron CA. Fibro-osseous lesions of the jaws. J Oral Maxillofac Surg 1993 Aug;51(8):828-835.

20. Johnson LC, Yousefi M, Vinh TN, Heffner DK, Hyams VJ, Hartman KS. Juvenile active ossifying fibroma. Its nature, dynamics and origin. Acta Otolaryngol Suppl 1991;488:1-40.

21. Rinaggio J, Land $M$, Cleveland DB. Juvenile ossifying fibroma of the mandible. J Pediatr Surg 2003 Apr;38(4):648-650.

22. Noffke CE. Juvenile ossifying fibroma of the mandible. An 8 year radiological follow-up. Dentomaxillofac Radiol 1998 Nov;27(6):363-366.

23. Bendet E, Bakon M, Talmi YP, Tadmor R, Kronenberg J. Juvenile cemento-ossifying fibroma of the maxilla. Ann Otol Rhinol Laryngol 1997 Jan;106(1):75-78.

24. Ong AH, Siar CH. Cemento-ossifying fibroma with mandibular fracture: case report in a young patient. Aust Dent J 1998 Aug;43(4):229-233.

25. Sun G, Chen X, Tang E, Li Z, Li J. Juvenile ossifying fibroma of the maxilla. Int J Oral Maxillofac Surg 2007 Jan;36(1):82-85. 